\title{
Size and resin fractionations of dissolved organic matter and trihalomethane precursors from four typical source waters in China
}

\author{
Qunshan Wei • Dongsheng Wang • Qia Wei • \\ Chunguang Qiao $\cdot$ Baoyou Shi $\cdot$ Hongxiao Tang
}

Received: 27 December 2006 / Accepted: 27 August 2007 /Published online: 13 September 2007

(C) Springer Science + Business Media B.V. 2007

\begin{abstract}
Dissolved organic matter (DOM) and its potential to form disinfection by-products (DBPs) during drinking water treatment raise challenges to water quality control. Understanding both chemical and physical characteristics of DOM in source waters is key to better water treatment. In this study, the DOM from four typical source waters in China was fractionated by XAD resin adsorption (RA) and ultrafiltration (UF) techniques. The trihalomethane formation potential (THMFP) of all fractions in the DOM were investigated to reveal the major THM precursors. The fraction distributions of DOM could be related to their geographical origins in a certain extent. The dominant chemical fraction as THM precursors in the DOM from south waters (East-Lake reservoir in Shenzhen and Peal rivers in Guangzhou)
\end{abstract}

Q. Wei $\cdot$ D. Wang $(\bowtie) \cdot$ Q. Wei $\cdot$ C. Qiao $\cdot$ B. Shi $\cdot$ H. Tang State Key Laboratory of Environmental Aquatic Chemistry, Research Center for Eco-Environmental Sciences,

Chinese Academy of Sciences,

Beijing 100085, China

e-mail: wgds@rcees.ac.cn

Q. Wei

Institute of Urban Environment,

Chinese Academy of Sciences,

Xiamen 361003, China

Q. Wei

Department of Environmental and Chemical Engineering,

Nanchang Institute of Aeronautical Technology,

Nanchang 330063, China was hydrophobic acid (HoA). The size fraction with molecular weight (MW) $<1 \mathrm{kDa}$ in both south waters had the highest THMFP. The results of cluster analysis showed that the parameters of fractions including DOC percentage (DOC \%), $\mathrm{UV}_{254} \%$, $\mathrm{SUVA}_{254}$ (specific $\mathrm{UV}_{254}$ absorbance) and THMFP were better for representing the differences of DOM from the studied waters than specific THMFP (STHMFP). The weak correlation between $\mathrm{SUVA}_{254}$ and STHMFP for either size or XAD fractions suggests that whether $\mathrm{SUVA}_{254}$ can be used as an indicator for the reactivity of THM formation is highly dependent on the nature of organic matter.

Keywords Dissolved organic matter - Disinfection by-products $\cdot$ Fractionation $\cdot$ Trihalomethane formation potential $\cdot$ Ultrafiltration $\cdot \mathrm{UV}$ absorbance $\cdot \mathrm{XAD}$ resin

\section{Introduction}

The dissolved organic matter (DOM) is commonly defined as materials that can pass a $0.45 \mu \mathrm{m}$ pore filter (Edzwald 1993). DOM can not only cause the aesthetic concerns such as color, taste and odor but also lead to the binding and transport of organic and inorganic contaminants and even produce undesirable disinfection by-products (DBPs) (Leenheer and Croue 2003). Significantly, trihalomethanes (THMs), one category of DBPs, are identified as potential carci- 
nogens and called for stricter control by recent legislation around the world (Sharp et al. 2006). Therefore, understanding the properties of DOM has always been one of the most significant research topics for water quality control. It is noticeable that both chemical and physical properties of DOM play important roles in the processes such as coagulation, filtration and disinfection. Therefore, it is necessary to understand both the physical and chemical characteristics of DOM, including the molecular weight (MW) or molecular size, hydrophobicity, THM formation potential (THMFP), UV absorbance (UV), for selecting the effective water purification processes.

Resin adsorption (RA) and ultrafiltration (UF) have commonly and successfully been employed in characterization of the chemical and physical properties of DOM from natural waters in past years. RA chromatographic separation method fractionates or isolates DOM components into operationally defined fractions depending on their affinities to different resins and their back-elution efficiencies (Kitis et al. 2002). Generally, XAD-8 (or DAX-8) and XAD-4 resin are used to fractionate DOM into hydrophobic and hydrophilic fractions, normally known as humic/ nonhumic distribution (Leenheer and Croue 2003). Significantly, the same fractionation protocols and a constant $k^{\prime}$ (capacity factor) should be maintained for comparing DOM from different waters (Leenheer 1981; Kitis et al. 2002).

Sequential UF is used for low-resolution separations. In theory, UF is a simple process: under hydrostatic pressure, solute molecules smaller than the size cut-off of the membrane are passed, along with solvent, through the micro-pores of the membrane; larger solutes are retained and concentrated (Aiken 1984). The advantages of UF methods are that no chemical reagents need to be added into the samples and the nature of DOM can be maintained in original state, which is very important for the effective characterization of DOM (Croue 2004). Moreover, it is also important to use similar concentration factors (CF) and the same operating conditions in order to compare UF results among samples and laboratories (Guo and Santschi 1996).

Many of studies varied in experimental procedures, and the sampling seasons were not uniform. Furthermore, there is no research focused on both chemical and physical fractional properties of DOM from four main source waters in China using RA and UF methods. Therefore, the objectives of this study are 1) to reveal both the chemical and physical characteristics of DOM from different waters samples which were collected in the same season and fractionated under the same experimental protocols; 2) to provide basic data of water qualities for water treatment researches.

\section{Materials and methods}

Sampling and source waters

All raw water samples were collected in the same season (Spring, 2005) from the intakes of four drinking water treatment plants (WTP) supplied by four main source waters in China: the Ninth WTP of Beijing Water Group Company (WGC) uses the Miyun reservoir $\left(40^{\circ} 18^{\prime} \mathrm{N}, 116^{\circ} 45^{\prime} \mathrm{E}\right)$ as its water source, the Jieyuan WTP of Tianjin WGC obtains the water from the Huanghe river $\left(39^{\circ} 07^{\prime} \mathrm{N}, 116^{\circ} 52^{\prime} \mathrm{E}\right)$, the Xicun WTP of Guangzhou WGC uses the water from Pearl river $\left(22^{\circ} 59^{\prime} \mathrm{N}, 113^{\circ} 03^{\prime} \mathrm{E}\right)$ and the EastLake WTP of Shenzhen WGC uses the East-Lake reservoir $\left(22^{\circ} 34^{\prime} \mathrm{N}, 114^{\circ} 08^{\prime} \mathrm{E}\right)$ as its source water.

Each kind of water sample was collected in a precleaned $500 \mathrm{ml}$ glass bottle and total five times in the sampling day. Samples collected in a day for each kind of waters were blended into a larger bottle and cooled immediately in an ice cooler after sampling. The sample was filtered through $0.45 \mu \mathrm{m}$ membrane within $24 \mathrm{~h}$ after mixed and always stored in a dark room at $4{ }^{\circ} \mathrm{C}$ before and after fractionation.

Fractionation of DOM by resin adsorption

The method of resin adsorption used in this study was modified from Leenheer's and Martin-Mousset's methods (Leenheer 1981; Martin-Mousset et al. 1997). Because of the stable and other prominent properties (Aiken et al. 1979), nonionic resins (Amberlite XAD-8 and XAD-4) rather than ionic resins were selected in the modified method. The resins were cleaned and conditioned as described by Leenheer (1981). The ratio of water sample volume to XAD-8 or XAD-4 resin volume (wet volume) was set at $35: 1$ for avoiding fractions breakthrough and the initial water volume was $350 \mathrm{ml}$. The corresponding column capacity factor $\left(k^{\prime}\right)$ was 50 and the column 
void volume was $26.5 \%$ of total wet resin volume as recommended by manufacturer. The flow rate of loading sample onto the resins was lower than 30 bed-volumes $\mathrm{h}^{-1}$, normally 15 bed-volumes $\mathrm{h}^{-1}$, which permitted an adequate adsorption.

A schematic diagram of DOM fractionation procedure is illustrated in Fig. 1a. The steps were as following: (1) The filtered sample was first passed through XAD-8 resin without any $\mathrm{pH}$ adjustment to isolate the hydrophobic bases $(\mathrm{HoB})$ and hydrophobic neutral fraction (HoN). (2) HoB was back-washed out immediately with 10 bed-volumes $0.1 \mathrm{~mol} \mathrm{l}^{-1} \mathrm{H}_{3} \mathrm{PO}_{4}$ (all reagents used in this experiment are Guaranteed reagents) at 15 bed-volumes $h^{-1}$. The hydrophobic neutral $(\mathrm{HoN})$ couldn't be desorbed and retained in the resin. $\mathrm{H}_{3} \mathrm{PO}_{4}$ was selected because of its minimum impact on the dissolved organic carbon (DOC) measurement than $\mathrm{HCl}$ or $\mathrm{HNO}_{3}$ and $\mathrm{H}_{3} \mathrm{PO}_{4}$ is also recommended by the manufacturer of TOC instrument (Phoenix 8000). (3) The sample effluent (not back-washed effluent) from XAD-8 column was then adjusted to $\mathrm{pH} 2$ by $85 \% \mathrm{H}_{3} \mathrm{PO}_{4}$ and loaded onto this
XAD-8 resin column again. The hydrophobic acid (HoA) was adsorbed. (4) Then, the effluent having been adsorbed by XAD-8 resin twice was passed through XAD-4 resin. The fraction adsorbed by XAD-4 resin could be described as weakly hydrophobic acid (WHoA) (Bolto et al. 1998), which is also commonly defined as transphilic acid (THPA) (Leenheer and Croue 2003). (5) Organics contained in the last effluent (not retained on both XAD-8 and XAD-4 resins) were named hydrophilic matter (HiM).

To avoid the problem of losses upon concentration or isolation in preparative procedure, the quantitative method from Martin-Mousset et al. (1997) and Imai et al. (2001) was adopted. The quantities (DOC, $\mathrm{UV}_{254}$ and THMFP) of each fraction of DOM (except HoB) were determined based on the difference between the influent and the effluent. The advantage of this determination is that the influence of inorganic matter on the chlorination of DOM in actual water treatment is considered because the ratio of inorganic matter to DOM in actual treatment will increase gradually along the process units. The concentration of $\mathrm{HoB}$
Fig. 1 Schematic diagrams of the procedures for DOM fractionation. a Fractionation of DOM by resin adsorption. b Fractionation of DOM by ultrafiltration
Step 3: The effluent from XAD-8 was acidified to pH 2 and passed through the colurur again

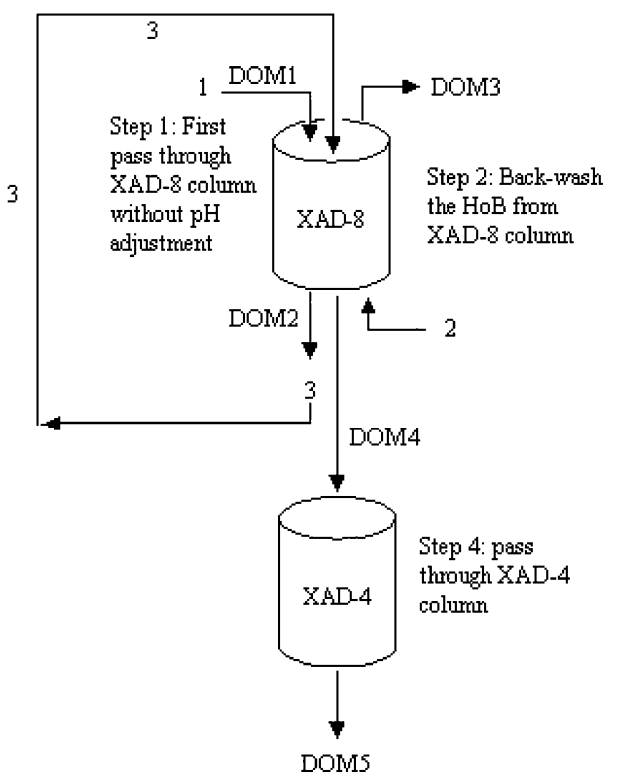

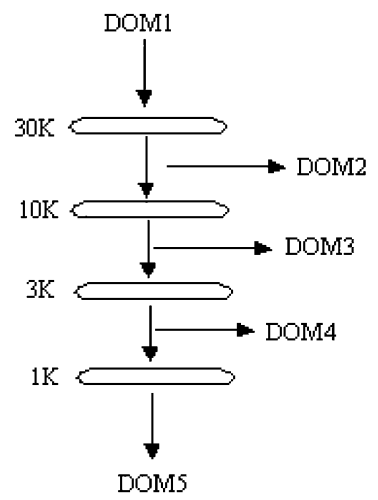


fraction was calculated by mass balance. Each DOM fraction was calculated as following functions:

$\mathrm{HoB}=(\mathrm{DOM} 3-\mathrm{B} 1) \times($ back - eluant volume $) /$

(sample volume), where B1 is the blank of back -

washed solution,

$\mathrm{HoN}=\mathrm{DOM} 1-\mathrm{DOM} 2-\mathrm{HoB}$,

HoA $=$ DOM2 - DOM4,

WHoA = DOM4 - DOM5,

$\mathrm{HiM}=$ DOM5

Where DOM1, DOM2, DOM3, DOM4, DOM5 are shown in Fig. 1a.

After the resins were cleaned carefully, the ultrapure water and $\mathrm{pH} 2$ acidic solution also prepared by ultra-pure water were alternately passed through the resin columns just before adding samples, and the effluent DOC were measured immediately to make sure the blanks of columns were as low as near to zero and negligible. (The blank of column also refers to the difference between the DOC concentration of influent pure water or $\mathrm{pH} 2$ pure water and that of effluent.) Therefore, the blanks of columns were not included in the calculation formulas of HoN, HoA, WHoA and HiM. In addition, fractionation experiments, both RA and UF, were all with duplicate samples.

Size fractionation of DOM by ultrafiltration

Ultrafiltration was performed by using a stirred ultrafiltration cell (Millipore, 8200) with YM disc membranes (Amicon, nominal MW cut-offs are 1, 3, 10 and $30 \mathrm{kDa}$ ). In each step, the volumes of sample and retentate were based on a constant concentration ratio of 6:1 (Amy et al. 1987). Concentration ratio or concentration factor $(\mathrm{CF})$ is defined as the ratio of the feed sample volume to the retentate volume. The DOC mass balance of our ultrafiltration system had been controlled in $(100 \pm 5) \%$ following the cleaning procedure used by Aiken (1984) and Guo and Santschi (1996) to achieve that losses or contamination problems during ultrafiltration were negligible. Membranes were first soaked several times (no less than three times during $24 \mathrm{~h}$ ) in a beaker of ultra-pure water, skin side down, to remove glycerin, which was added by the manufacturer to the membrane to prevent drying in shipment. Each time when the pure water in the beaker changed, the membrane needed to be flushed thoroughly. After soaked, the membrane was installed into the ultrafiltration cell and rinsed two times, alternating from $0.01 \mathrm{~mol} \mathrm{l}^{-1} \mathrm{NaOH}$ to $0.01 \mathrm{~mol} \mathrm{l}^{-1} \mathrm{HCl}$, with the stirrer agitating more than $10 \mathrm{~min}$ each time. Prior to filtering sample the apparatus was rinsed with ultra-pure water more than three times, and $100 \mathrm{ml}$ of this water was passed through the membrane to remove any contingent organic impurity from pores.

To minimize concentration polarization effects, we used a series of filtration steps in which highmolecular-weight molecules could be removed first. The filtrate in the former step was applied as feed sample in the next step and the retentate was also collected to measure the concentration of DOC to control the DOC mass balance. The concentration of each fraction was based on the difference between the concentration of feed sample and that of permeate in each filtration step. The initial sample volume of $442 \mathrm{ml}$ was needed in the first filtration step and $150 \mathrm{ml}$ of permeate volume would be obtained in the last step according to the CF of $6: 1$. Pressure was supplied with nitrogen gas (99.99\%) from 20 to $35 \mathrm{kPa}$ and the actual pressure employed for a given membrane was based on the flow rate recommended by the manufacturer. The schematic diagram of size fractionation of DOM is shown in Fig. 2b. The DOC mass balance or recovery was checked as (\%recovery $)=\left(C_{\mathrm{p}} V_{\mathrm{p}}+C_{\mathrm{r}} V_{\mathrm{r}}\right) /\left(C_{0} V_{0}\right)$, where $V_{0}, V_{\mathrm{p}}$ and $V_{\mathrm{r}}$ are the volume of feed, permeate and retentate sample, respectively, and $C_{0}, C_{\mathrm{p}}$ and $C_{\mathrm{r}}$ are the DOC concentrations of feed, permeate and retentate sample, respectively (Guo and Santschi 1996).

\section{Chemical analysis}

All samples including raw water filtered through $0.45 \mu \mathrm{m}$ membrane, eluates, effluents from resin columns and permeates through ultrafiltration membranes were analyzed for DOC, $\mathrm{UV}_{254}$ and THMFP. DOC was measured with a Phoenix 8000 TOC Analyzer (Tekmar Dohrmann, USA) using the UV/ Persulphate oxidation method. The instrument error was controlled within 3\% with run of standards after every ten samples. $\mathrm{UV}_{254}$ was measured with a DR/ 4000 U Spectrophotometer (HACH, USA) with a $1-\mathrm{cm}$ quartz cell at $254 \mathrm{~nm}$. Specific ultraviolet absorbance $\left(\mathrm{SUVA}_{254}\right)$ is defined as the $\mathrm{UV}_{254}$ 
absorbance divided by the DOC concentration. The $\mathrm{pH}$ effects to UV absorbances of all water samples were considered and proved to be negligible.

THMFP was measured according to the Standard Methods (APHA et al. 1995) for the examination of drinking water (5710B and 6232B). The neutralized samples were buffered by a phosphate solution prior to the incubation at $25 \pm 2^{\circ} \mathrm{C}$ in amber bottles with PTFE (poly-Teflon) liners. At the end of 7 days reaction period, samples with a remaining free chlorine residual of 3-5 $\mathrm{mg} \mathrm{l}^{-1}$ as $\mathrm{Cl}_{2}$ were analyzed for THMs by the gas chromatography instrument (PerkinElmer Autosystem XL, USA.) with an electron capture detector (ECD) and a capillary column (OV$17, \Phi 0.32 \mathrm{~mm} \times 30 \mathrm{~m} \times 0.25 \mu \mathrm{m})$. Pesticide grade $N$ hexane was used as extraction solvent and the oven temperature program was $70^{\circ} \mathrm{C}$ holding $2 \mathrm{~min}$, ramp $20^{\circ} \mathrm{C} \mathrm{min}^{-1}$ to $100^{\circ} \mathrm{C}$, then $10^{\circ} \mathrm{C} \mathrm{min}^{-1}$ to $120^{\circ} \mathrm{C}$ for $2 \mathrm{~min}$. The injection volume was $1 \mu \mathrm{l}$ and split injection ratio was set at 30:1 for appropriate signal range and sensitivity. THMs were quantified by external standard procedure and the minimum detectable limitations (MDL) of $\mathrm{CHCl}_{3}, \mathrm{CHCl}_{2} \mathrm{Br}, \mathrm{CHClBr}_{2}, \mathrm{CHBr}_{3}$ were $0.0049 \mu \mathrm{g} \mathrm{l}^{-1}, 0.0024 \mu \mathrm{g} \mathrm{l}^{-1}, 0.0032 \mu \mathrm{g} \mathrm{l^{-1 }}$, $0.0088 \mu \mathrm{g} \mathrm{l}^{-1}$, respectively. The reproducibility of instrument measurement was controlled in 5\% with at least triplicate measurements. The STHMFP (specific THMFP) was calculated as THMFP divided by the DOC concentration. Moreover, The STHMFP of HoB and $\mathrm{HoN}$ were presented in a total parameter as HoB\&N because of the lower concentration of HoB. THM concentrations was reported as a single value as micrograms $\mathrm{CHCl}_{3}$ per liter $\left(\mu \mathrm{g} \mathrm{CHCl}_{3} 1^{-1}\right)$ and calculated as $\mathrm{THM}=\mathrm{A}+0.728 \mathrm{~B}+0.574 \mathrm{C}+0.472 \mathrm{D}$, where $\mathrm{A}=\mu \mathrm{g} \mathrm{CHCl}_{3} \mathrm{l}^{-1}, \mathrm{~B}=\mu \mathrm{g} \mathrm{CHBrCl}_{2} \mathrm{l}^{-1}, \mathrm{C}=\mu \mathrm{g}$ $\mathrm{CHBr}_{2} \mathrm{Cl} \mathrm{l}^{-1}, \mathrm{D}=\mu \mathrm{g} \mathrm{CHBr} \mathrm{l}^{-1}$.

\section{Results and discussion}

\section{Chemical fractions of DOM}

The fraction distributions of the DOM from both south waters (Shenzhen East-Lake reservoir and Guangzhou Peal river) were similar to each other although the total DOC, $\mathrm{UV}_{254}$ and THMFP were clearly different (Fig. 2). The dominant component in both south waters was hydrophobic acid (HoA), accounting for about $40 \%$ as DOC content, which was also the main THM precursor with a relative contribution of around $40 \%$ to the total THMFP. The hydrophilic matter (HiM) for both source waters was the second largest fraction (about $25 \%$ as DOC content). Moreover, the $\mathrm{SUVA}_{254}$ of the chemical fractions from both waters were also identical (Fig. 3). Both of the waters are located at Guangdong province in the South of China and close to each other (Guangzhou water at $22^{\circ} 59^{\prime} \mathrm{N}, 113^{\circ} 03^{\prime} \mathrm{E}$ and Shenzhen water at $22^{\circ} 34^{\prime} \mathrm{N}, 114^{\circ} 08^{\prime}$ E). This indicates that the chemical fraction distributions of DOM may be related to the geographic origins of
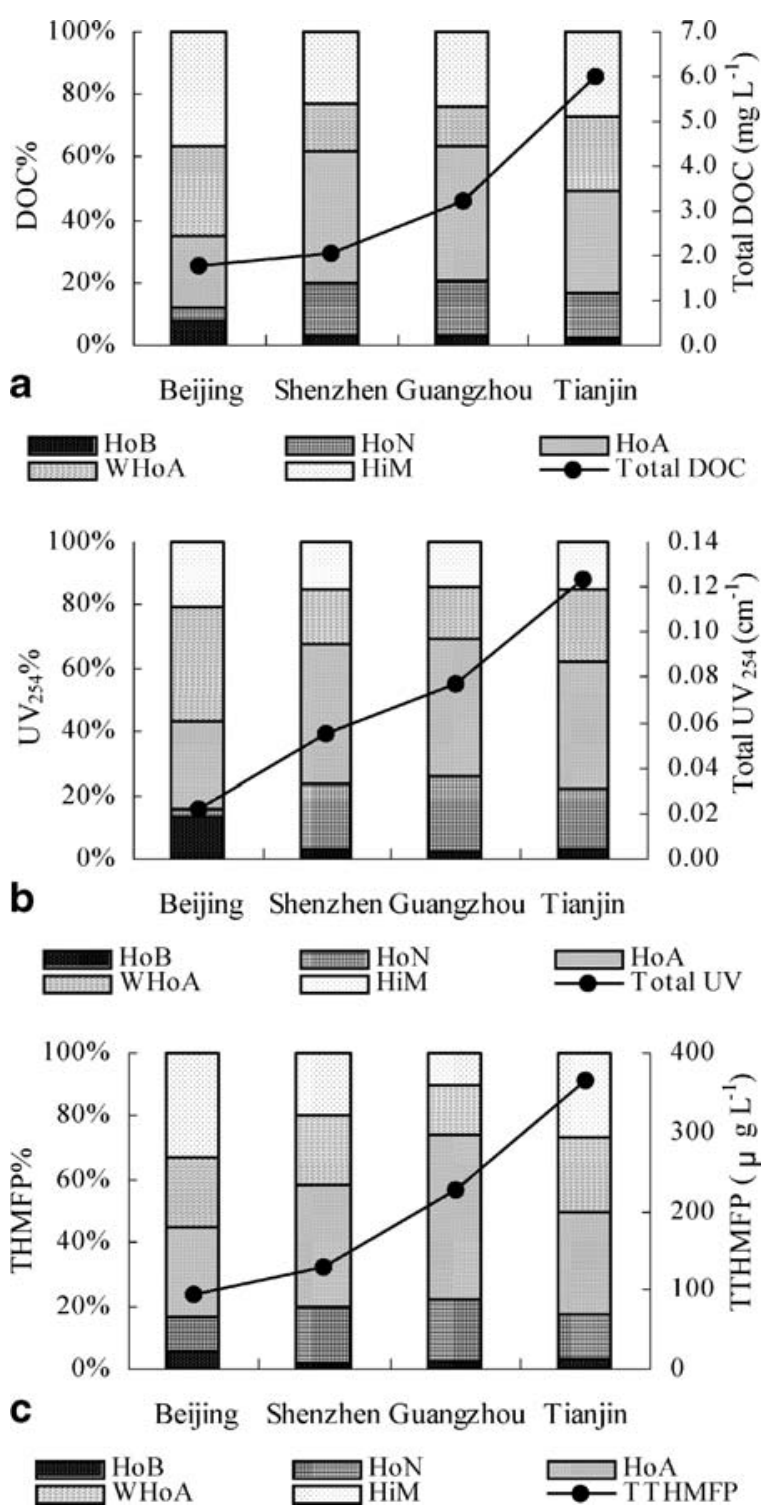

Fig. 2 The a DOC $\%$, b $U_{254} \%$ and $\mathbf{c}$ THMFP\% of chemical fractions of DOM from four typical source waters in China 

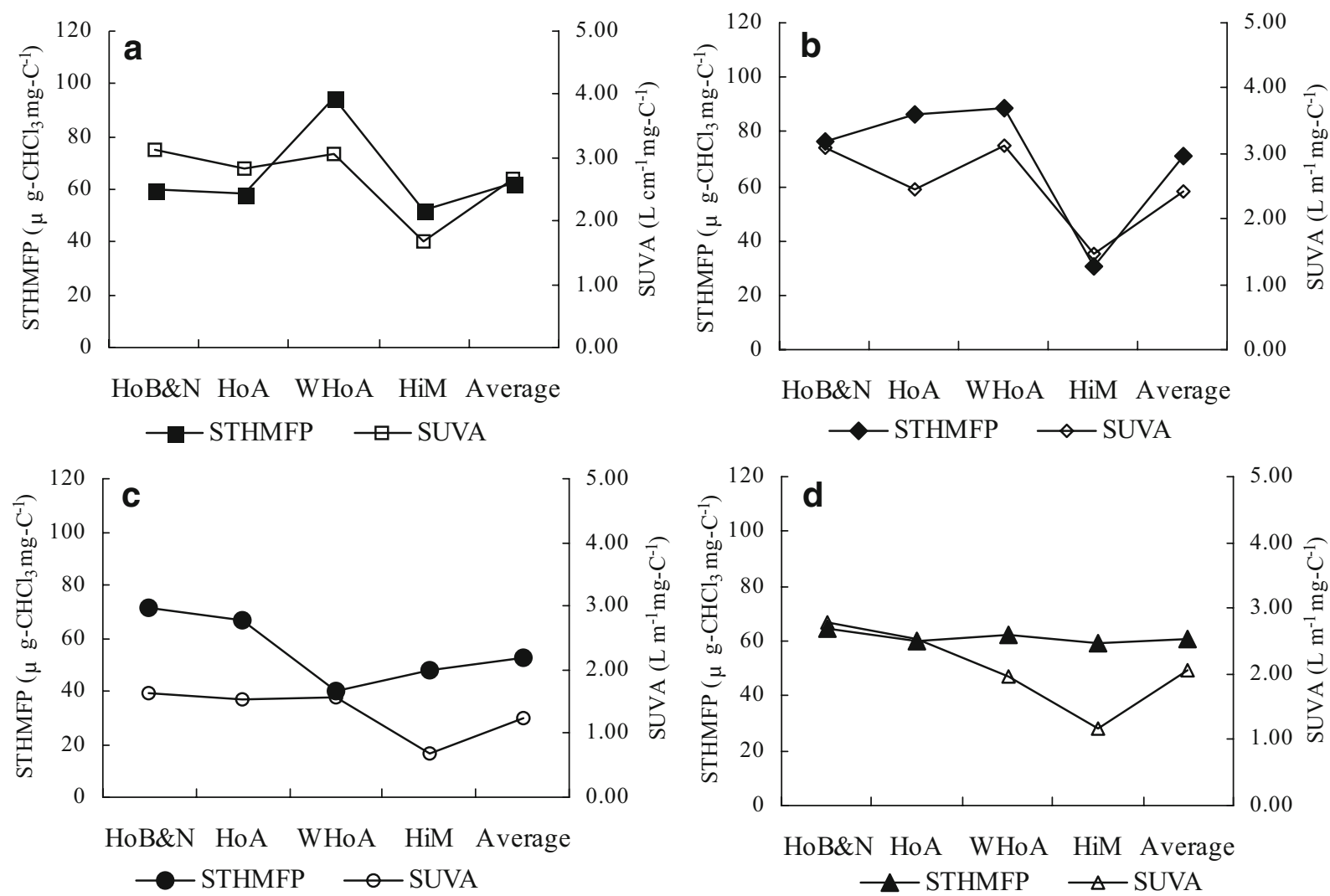

Fig. 3 STHMFP and SUVA of chemical fractions of DOM from four different waters: a Shenzhen water, b Guangzhou water, c Beijing water, $\mathbf{d}$ Tianjin water

the DOM. The consistent fractional characteristics of the DOM from the two south waters were further proved exactly by the cluster results processed by SPSS (13.0) software (Table 1). The hierarchical cluster method was adopted as follows: cases (waters) cluster, between-groups linkage and squared Euclidean distance. The lower the coefficients of the cluster results, the closer the waters are.

Furthermore the DOM from river water exhibited a consistent chemical fraction distribution. The Shenzhen water (East-Lake reservoir), which is supplied by the East River in the Guangdong province, and other river waters (Pearl river of Guangzhou, Huanghe river of Tianjin) tended to be classified into one category in the stage 2 cluster by SPSS based on the parameters of DOC $\%, \mathrm{UV}_{254} \%$ and $\mathrm{SUVA}_{254}$ off chemical fractions (Table 1). The HoA predominated in the DOM from these riverine waters not only by the highest relative contribution to total DOC (i.e. DOC\%), but also the UV\%, and THMFP\% (Fig. 2). This consistent with reported result (Imai et al. 2001) that HoA was dominant constituent of riverine DOM. Chiang et al. (2002) also found that the hydrophobic constituents were more commonly observed than hydrophilic constituents in some surface waters.

Whereas the fractional characteristic of DOM from Beijing water (Miyun reservoir) was distinguished by that the HiM fraction dominated in the water with the largest percent of $36 \%$ as DOC content. It should be noticed that the distribution parameters of THMFP $\%$ and STHMFP are less applicable to classify various waters than $\mathrm{DOC} \%$ and $\mathrm{UV}_{254} \%$ (Tables 1 and 2).

\section{Size distributions of DOM}

As showed in the Figs. 4a,c, 5a,b and Table 2, the size distributions of the DOM from these waters also exhibited geographical characteristic as that of chemical fractions. The basic MW distributions of the DOM from both south waters (Guangzhou and 


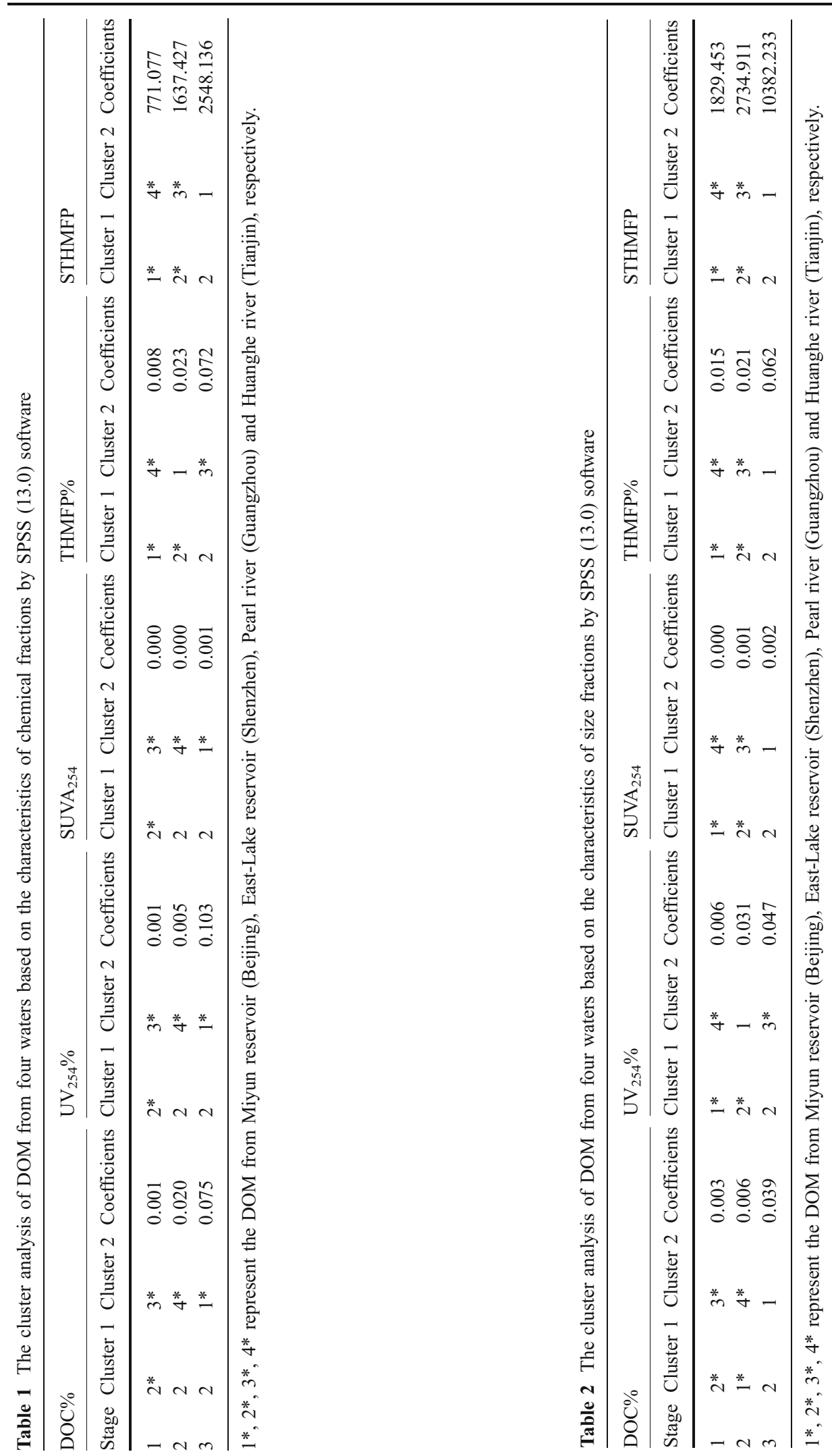


Shenzhen) were similar to each other. The organic matter with $\mathrm{MW}<1$ and 10-30 kDa were richer than other size fractions, which accounting for around $35 \%$ and $24 \%$ as DOC content, respectively. They were also significant THM precursors in the DOM (Fig. 5c). Moreover, there existed similar trend between the STHMFP and $\mathrm{SUVA}_{254}$ for the size fractions (except the $>30 \mathrm{kDa}$ fraction) from both south waters (Fig. 5a,b).

The size distributions of DOM from both north waters (Beijing and Tianjin) also presented some degrees of similarity (Figs. 4 and $5 \mathrm{c}, \mathrm{d}$ ), and the cluster results of $\mathrm{UV}_{254} \%, \mathrm{SUVA}_{254}$ and $\mathrm{THMFP} \%$ proved it exactly (Table 2). The size distributions of south waters (Shenzhen, Guangzhou) were distinct from that of north waters in the amounts of 10 $30 \mathrm{kDa}$ fraction (Fig. 4), especially in the DOC\% and THMFP\% of this fraction (Fig. 4a,c). In addition, it was noticeable that the $<1 \mathrm{kDa}$ fraction was the predominant constituent (around 40\%) as THM precursors in the DOM from all four waters (Fig. 4c), which may attribute to the highest DOC content (35-40\%) of this fraction (Fig. 4a). For other source waters such as the influent of Myrtle Beach WTP in Carolina and Tomhannoc reservoir in New York, the $<1 \mathrm{kDa}$ fraction also dominated the DOM composition and comprised $44 \%$ and $51 \%$ of the total DOC, respectively (Kitis et al. 2002).

\section{STHMFP and SUVA254}

SUVA $_{254}$ could be widely utilized as a surrogate measurement for DOC aromaticity based on earlier studies (Chin et al. 1997) and $\mathrm{SUVA}_{254}$ was further observed strongly correlated with percent aromaticity as determined by ${ }^{13} \mathrm{C}$ NMR (nuclear magnetic resonance) (Weishaar et al. 2003; Croue 2004). When the polyhydroxy aromatic structures present in humic substances was recognized as the main THM precursors (Rook 1976), similar results have been reported in past years that the reactivity of DOC and aquatic humic substances with chlorine is strongly dependent on the aromaticity of the organic matter ( $\mathrm{Li}$ et al. 2000). Therefore, $\mathrm{SUVA}_{254}$ is often used in the water industry as a surrogate parameter to estimate the yields of THM precursors (STHMFP) in source waters (Edzwald et al. 1985; Kitis et al. 2002). But the earlier work also led investigators to conflicting conclusions with regard to the application of
$\mathrm{SUVA}_{254}$ to estimate aromaticity of aquatic humic substances (Weishaar et al. 2003). Not all aromatic carbons show equal absorbency for UV spectrometry and reactivity in THM formation (Chow et al. 2005). The same aromatic carbons with different functional groups (Chang et al. 2006) or the same DOM fractions from different source waters (Chow et al. 2005) may differ in SUVA $_{254}$ and STHMFP. Especially, Chow et al. (2005) suggested that the information from a particular water sources should not be simply applied to different water sources, and only carbon normalized THMFP with the same testing

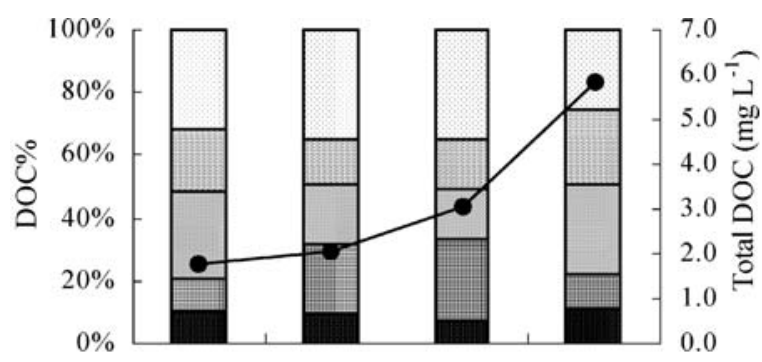

a Beijing Shenzhen Guanghou Tianjin
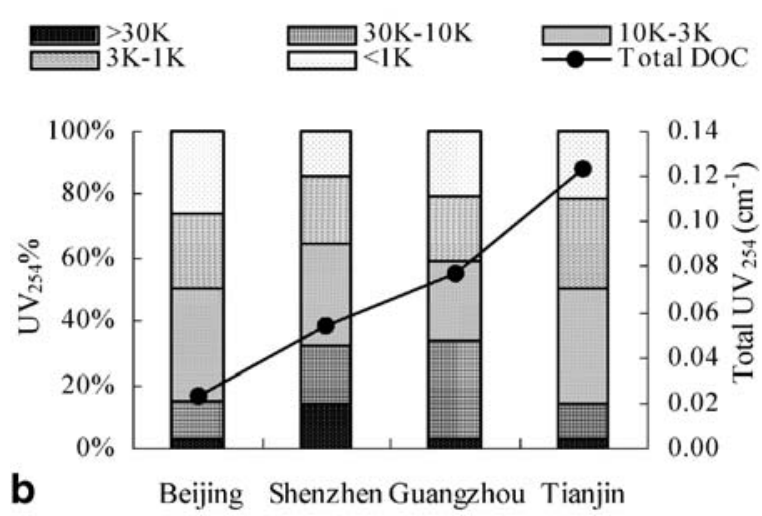

b Beijing Shenzhen Guangzhou Tianjin
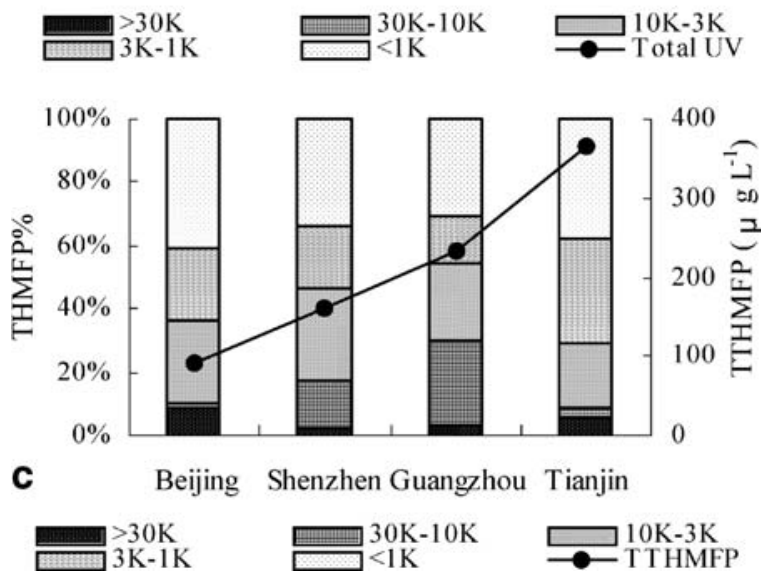

Fig. 4 The a DOC $\%$, b UV254\% and c THMFP\% of size fractions of DOM from four source waters in China 

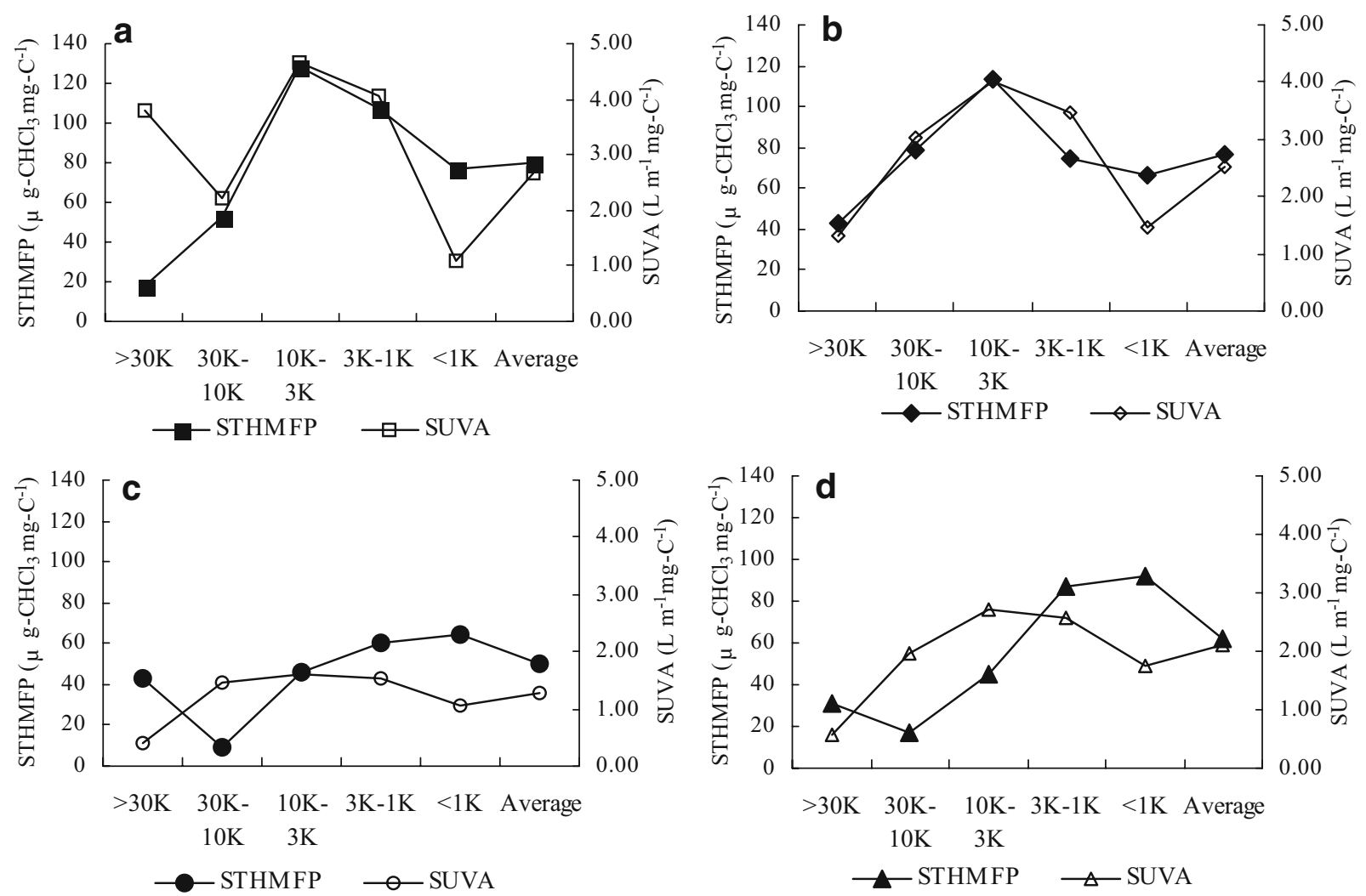

Fig. 5 STHMFP and SUVA of physical fractions of DOM from four different waters: a Shenzhen water, b Guangzhou water, c Beijing water, $\mathbf{d}$ Tianjin water

procedures or protocols should be used. Using same experimental method, Weishaar et al. (2003) found there was also no significant correlation between SUVA $_{254}$ and STHMFP, and $\mathrm{SUVA}_{254}$ was a weak universal indicator of reactivity for the formation of THMs for whole water samples based on the data of 34 samples from major river systems throughout the United States.

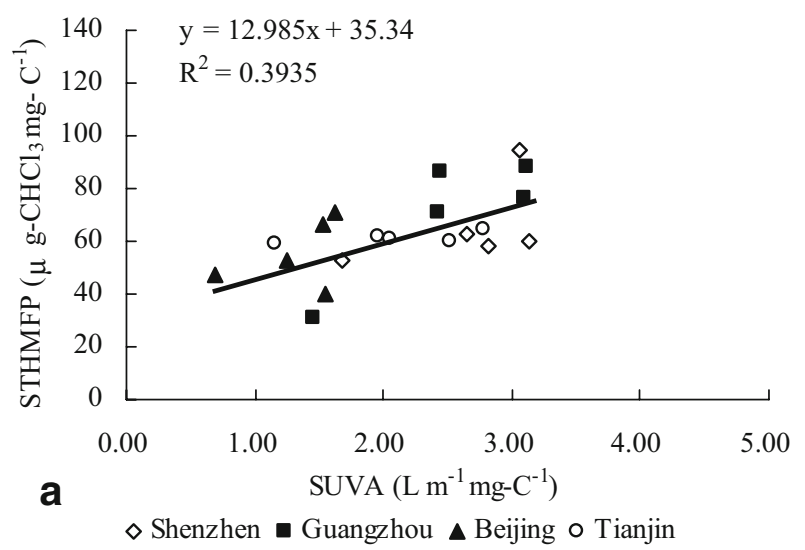

Our research indicated that the correlation between SUVA $_{254}$ and STHMFP was also weak for the fractions of DOM (Figs. 3, 5 and 6). Both the HoA from Guangzhou water and HiM from Tianjin water had low $\mathrm{SUVA}_{254}$ value, while the corresponding STHMFP were relatively high. In addition, the WHoA from Beijing water was higher in $\mathrm{SUVA}_{254}$ than other fractions but showed the lowest reactivity

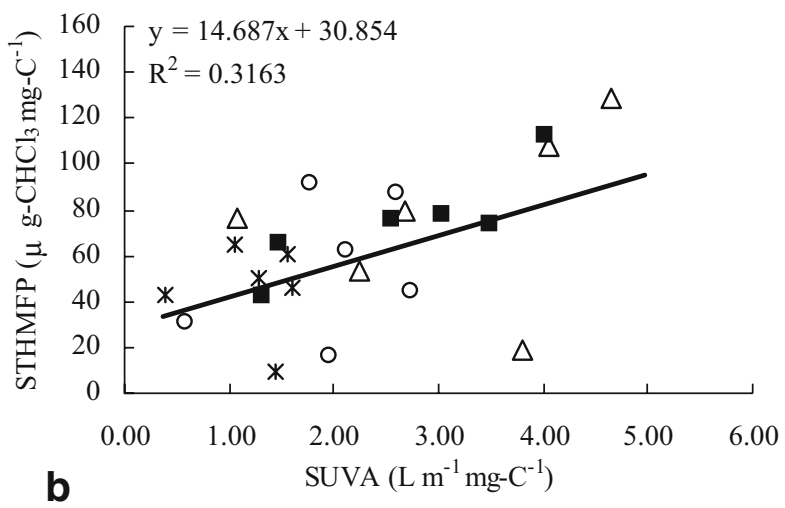

$\triangle$ Shenzhen Guangzhou $*$ Beijing $\circ$ Tianjin

Fig. 6 Correlations between STHMFP and SUVA for a chemical fractions and b physical fractions of DOM from four source waters 
for the formation of THMs (Fig. 4c). The inconsistency between $\mathrm{SUVA}_{254}$ and STHMFP has also been found in recent studies for HoN fraction (Panyapinyopol et al. 2005) and AHS (aquatic humic substances) (Imai et al. 2003). The data of correlation between $\mathrm{SUVA}_{254}$ and STHMFP for the size fractions also appeared significant scatter (Fig. 6b).

Moreover, the same fractions from different waters would exhibited different characteristics in $\mathrm{UV}_{254}$ absorbency and THM yields. For example, as showed in Fig. 3, the WHoA of both Shenzhen and Guangzhou water had the highest STHMFP, accounting for around $95 \mu \mathrm{g} \mathrm{CHCl}_{3} \mathrm{mg} \mathrm{C}^{-1}$, while the STHMFP of the same fractions from Beijing and Tianjin water were around 40 and $60 \mu \mathrm{g} \mathrm{CHCl}_{3} \mathrm{mg} \mathrm{C} \mathrm{C}^{-1}$, respectively. The $\mathrm{SUVA}_{254}$ values of HoB\&N, HoA and WHoA from Shenzhen water were apparently different from that of Beijing water (Fig. 3a,c). The same size fractions from different waters would also show different characteristics (Fig. 5).

SUVA $_{254}$ may be a good variable in cluster analysis for distinguishing DOM from diverse waters (Tables 1 and 2), but whether the $\mathrm{SUVA}_{254}$ could be used as a surrogate parameter for predicting the reactivity of DOM with chlorine is highly dependent on the nature of organic matter and the water.

\section{Implications for water treatment management}

The limitation of THMs in finished water has been promulgated in drinking water quality standard worldwide and stricter rules will be required for safer drinking water in future. Therefore, the THMFP of DOM in source waters should be paid more attention by water treatment utilities. The DOM of Tianjin water (Huanghe river) had the largest THMFP, accounting for $364.4 \mu \mathrm{g} \mathrm{l}^{-1}$ as $\mathrm{CHCl}_{3}$, which was higher than six times of the maximum limit for THMs in China $\left(60 \mu \mathrm{g} \mathrm{CHCl}_{3} \mathrm{l}^{-1}\right)$. The chemical fractions of HoA, HiM and WHoA in this water, each with a THMFP about $100 \mu \mathrm{g} \mathrm{CHCl}_{3} \mathrm{l}^{-1}$, were the main THM precursors, and it could attribute to their relatively high DOC percent. As to the size fractions of this water, low MW $(<10 \mathrm{kDa})$ components were higher on DOC $\%$, THMFP\%, and STHMFP than others. Therefore, enhanced treatment techniques (e.g. active carbon adsorption) should be taken into account to reduce the THMs concentrations in the finished water since most conventional processes are ineffective in removing small and hydrophilic organic molecules (Chang et al. 2001; Sharp et al. 2006). With the second highest THMFP $\left(228 \mu \mathrm{g} \mathrm{CHCl}_{3} \mathrm{l}^{-1}\right)$ was the DOM from Guangzhou water (Pearl river), of which HoA was the dominant chemical fraction and its DOC $\%$ and THMFP $\%$ account for $42 \%$ and $51 \%$, respectively. Moreover, the $<1 \mathrm{kDa}$ (35\% of total DOC, $31 \%$ of total THMFP) was the major size composition. Therefore, to improve the removal efficiencies of the THM precursors in Guangzhou water (Pearl river), the high hydrophobicity and low molecular weight distribution of the DOM should be considered entirely. It is also applicable to Shenzhen (East-Lake reservoir) water because the DOM from this water had the same fractional characteristics. The DOM of Beijing water (Miyun reservoir) had the lowest THMFP, accounting for around $100 \mu \mathrm{g} \mathrm{CHCl}_{3} \mathrm{l}^{-1}$, which is near the THMs limit of drinking water standard in China. Thus, the traditional treatment processes (e.g. coagulation and filtration) would be able to meet the requirement of drinking water regulation.

\section{Conclusion}

The fraction distributions of DOM from different waters related to the geographical origins of DOM in a certain extent. The dominant chemical fraction as THM precursors in the DOM from south waters (East-Lake reservoir in Shenzhen and Peal rivers in Guangzhou) was hydrophobic acid (HoA). The size fraction with molecular weight (MW) $<1 \mathrm{kDa}$ in both south waters had the highest THMFP. The results of cluster analysis showed that the parameters of fractions including $\mathrm{DOC} \%, \mathrm{UV}_{254} \%, \mathrm{SUVA}_{254}$ and THMFP were better for representing the differences of DOM from the studied waters than STHMFP. Moreover, the riverine DOM had a consistent fractional characteristic and tended to be clustered to one category. The weak correlation between $\mathrm{SUVA}_{254}$ and STHMFP for either size or resin isolated fractions suggests that whether $\mathrm{SUVA}_{254}$ can be used as an indicator for the reactivity of THM formation is highly dependent on the nature of organic matter.

Acknowledgements The authors gratefully acknowledge the financial support for this study from the China NSF through grant 20477054/50578155 and from the National 863 Program for safer drinking water technologies through grant 2002AA00601140. 


\section{References}

Aiken, G. R. (1984). Evaluation of ultrafiltration for determining molecular weight of fulvic acid. Environmental Science \& Technology, 18(12), 978-981.

Aiken, G. R., Thurman, E. M., \& Malcolm, R. L. (1979). Comparison of XAD macroporous resins for the concentration of fulvic acid from aqueous solution. Analytical Chemistry, 51(11), 1799-1803.

Amy, G. L., Collins, M. R., Kuo, C. J., \& King, P. H. (1987). Comparing gel permeation chromatography and ultrafiltration for the molecular weight characterization of aquatic organic matter. Journal - American Water Works Association, 79(1), 43-49.

Bolto, B. A., Dixon, D. R., Eldridge, R. J., \& King, S. J. (1998). The use of cationic polymers as primary coagulants in water treatment. In H. H. Hahn, E. Hoffmann, \& H. Ødeguard (Eds.), Chemical water and wastewater treatment $V$ (pp. 173-185). Berlin: Springer.

Chang, E. E., Chiang, P. C., Chao, S. H., \& Lin, Y. L. (2006). Relationship between chlorine consumption and chlorination by-products formation for model compounds. Chemosphere, 64(7), 1196-1203.

Chang, E. E., Chiang, P. C., Ko, Y. W., \& Lan, W. H. (2001). Characteristics of organic precursors and their relationship with disinfection by-products. Chemosphere, 44(5), 1231-1236.

Chiang, P. C., Chang, E. E., \& Liang, C. H. (2002). NOM characteristics and treatabilities of ozonation processes. Chemosphere, 46(6), 929-936.

Chin, Y. P., Aiken, G. R., \& Danielsen, K. M. (1997). Binding of pyrene to aquatic and commercial humic substances: The role of molecular weight and aromaticity. Environmental Science \& Technology, 31(6), 1630-1635.

Chow, A. T., Gao, S., \& Dahlgren, R. A. (2005). Physical and chemical fractionation of dissolved organic matter and trihalomethane precursors: A review. Journal of Water Supply: Research and Technology, 54(8), 475-507.

Croue, J. P. (2004). Isolation of humic and non-humic NOM fractions: Structural characterization. Environmental Monitoring and Assessment, 92(1-3), 193-207.

Edzwald, J. K. (1993). Coagulation in drinking water treatment: Particles, organics and coagulants. Water Science and Technology, 27(11), 21-35.

Edzwald, J. K., Becker, W. C., \& Wattier, K. L. (1985). Surrogate parameters for monitoring organic-matter and THM precursors. Journal - American Water Works Association, 77(4), 122-132.
Guo, L., \& Santschi, P. H. (1996). A critical evaluation of cross-flow ultrafiltration technique for sampling colloidal organic carbon in seawater. Marine Chemistry, 55(1-2), 113-127.

Imai, A., Fukushima, T., Matsushige, K., \& Kim, Y. H. (2001). Fractionation and characterization of dissolved organic matter in a shallow eutrophic lake, its inflowing rivers, and other organic matter sources. Water Research, 35(17), 4019-4028.

Imai, A., Matsushige, K., \& Nagai, T. (2003). Trihalomethane formation potential of dissolved organic matter in a shallow eutrophic lake. Water Research, 37(17), 4284- 4294.

Kitis, M., Karanfil, T., Wigton, A., \& Kilduff, J. E. (2002). Probing reactivity of dissolved organic matter for disinfection by-product formation using XAD-8 resin adsorption and ultrafiltration fractionation. Water Research, 36 (15), 3834-3848.

Leenheer, J. A. (1981). Comprehensive approach to preparative isolation and fractionation of dissolved organic carbon from natural waters and wastewaters. Environmental Science \& Technology, 15(5), 578-587.

Leenheer, J. A., \& Croue, J. P. (2003). Characterizing dissolved aquatic organic matter. Environmental Science \& Technology, 37(1), 18A-26A.

Li, C. W., Benjamin, M. M., \& Korshin, G. V. (2000). Use of UV spectroscopy to characterize the reaction between NOM and free chlorine. Environmental Science \& Technology, 34(12), 2570-2575.

Martin-Mousset, B., Croue, J. P., Lefebvre, E., \& Legube, B. (1997) Distribution and characterization of dissolved organic matter of surface waters. Water Research, 31(3), 541-553.

Panyapinyopol, B., Marhaba, T. F., Kanokkantapong, V., \& Pavasant, P. (2005). Characterization of precursors to trihalomethanes formation in Bangkok source water. Journal of Hazardous Materials, 120(1-3), 229-236.

Rook, J. J. (1976). Haloforms in drinking water. Journal American Water Works Association, 68(3), 168-172.

Sharp, E. L., Parsons, S. A., \& Jefferson, B. (2006). Seasonal variations in natural organic matter and its impact on coagulation in water treatment. Science of the Total Environment, 363(1-3), 183-194.

APHA, AWWA, \& WEF (1995). Standard methods for the examination of water and waste water (19th ed.). Washington, DC: APHA, AWWA, \& WEF.

Weishaar, J. L., Aiken, G. R., Bergamaschi, B. A., Fram, M. S., Fujii, R., \& Mopper, K. (2003). Evaluation of specific ultraviolet absorbance as and indicator of the chemical composition and reactivity of dissolved organic carbon. Environmental Science \& Technology, 37(20), 4702-4708. 